\title{
Launch of the Zambian Network of Critical Care
}

\section{Nurses}

Chris Carter RN; DiPHE, BSc(Hons), PGDip, Associate Nurse Lecturer, Faculty of Health, Education and Life Sciences, Birmingham City University, United Kingdom

Kevin Crimmons RN; BSc(Hons), PGDip, FHEA, Associate Professor \& Head of the Department of Adult Nursing, School of Nursing and Midwifery, Birmingham City University, United Kingdom

Pelile Gambwe RN, Registered Critical Care Nurse, Main Intensive Care Unit, University Teaching Hospital, Lusaka, Zambia

Key Words: critical care * developing world * international * network * professional association * Zambia *

E-mail: chris.carter@bcu.ac.uk

\section{SUMMARY}

Zambia is a low middle income country in sub-Saharan Africa. Critical Care Nursing is a relatively new speciality.

- This paper explores the current provision of critical care services and the development of a professional network to support critical care nurses.

\section{INTRODUCTION}

Critical Care Nursing in Zambia is a relatively new speciality in nursing and evolved into a recognised speciality in 2012. An increase demand for critical care services in response to an improving healthcare system and life expectancy has meant skilled critical care nurses are in demand.

Zambia is a low middle income country (LMIC), land-locked country in central Africa, and has a population of approximately 14 million. Although economic and social developments have occurred, the healthcare system faces a number of challenges due to a lack of healthcare staff, approximately $60 \%$ of the population live below the poverty line, with $42 \%$ living in extreme poverty (The World Bank, 2016). The provision of healthcare is also challenging with $60.5 \%$ of the population living in rural areas and $39.5 \%$ in urban areas (Central Statistics Office, 2013). Current life expectancy is 59 years for males and 65 for females [World Health Organisation (WHO), 2016].

\section{Zambian Healthcare}

With a large proportion of the population living in rural areas, the provision and access to a comprehensive healthcare service is complex. In addition, there is a significant shortfall in trained nurses and other healthcare professionals available to deliver the full spectrum of healthcare needs to the nation (World Health Organisation (WHO), 2015). Critical care services have gradually increased, with the first intensive care unit opening at the nations national tertiary referral hospital at The University Teaching Hospital in 1987 (Mwewa \& Mweembai, 2010). Since then 16 units across the country have been established, with the most recent in March 2016. In 2012, Critical Care Nursing was recognised as a speciality by the Ministry of Health and the General Nursing Council (GNC). A specialist post registration specialist course was commenced at the Lusaka School of Nursing. In 2015, 81 nurses were reported to have completed the programme (Mulenga et al., 2015). Within medicine, critical care is currently not a recognised speciality in its own right and tends to rely on physician anaesthetists and clinical officers to 'cover' critical care units. It is acknowledged the anaesthesia speciality within Zambia is under-resourced and developed, with practice largely confined to the intra-operative period and input into pain management and critical care remains limited (Kinnear et al., 2013). This has resulted in critical care nurses developing a broad scope of practice, which includes advanced airway management, weaning from ventilation and overall care of the critically ill patient.

With critical care nurses managing services across Zambia, with limited peer and inter-professional support, the need for a critical care nursing voice has been gradually gathering momentum nationally and internationally. A way to help facilitate this is through professional organisation partnering with a network. Since 2014, a team has been working with the Zambian Ministry of Health and a number of key nurses to help capacity build critical care nursing. This work was initially established in conjunction with the Tropical Health and Education Trust (THET) and the MMed Physician Anaesthesia programme (Carter, 2015). In 2016, the project progressed and Birmingham City University (BCU), a higher education intuition (HEI) in the United Kingdom became a lead project partner.

A key initial joint project between the Ministry of Health and BCU and a national needs assessment. The assessment explored the provision of critical care services in public hospitals. From discussions with various nurses it was identified critical care nurses often work in isolation, leading to what appears to be 'professional isolation'. This can be due to a lack of support from peers and other healthcare professionals within hospitals as well as minimal arrangements for professional support. In response to this and in conjunction with the Ministry of Health a critical care nursing network using social media was established in May.

The group now has 82 members and the aim of the network is to provide nurses with a professional platform to explore and discuss critical care issues, relevant to their practice. The objectives of the group are to:

- Provide a shared vision and strategy to assist in the development of a nursing workforce

- Provide a professional forum to share ideas and support

- Contribute to the broader multi-professional agenda of developing critical care services across Zambia.

To provide a greater international link, the network has recently joined the World Federation of Critical Care Nurses (WFCCN) as an associate member. By building links with the WfCCN, this will ensure 
Zambian nurses are at the centre of the project, informing, shaping and developing their practice. In addition, membership provides the opportunity to link and develop critical care nursing across subSaharan Africa.

In 2012, a survey of national critical care nursing organisations and activities identified only two African countries were represented (Williams et al., 2012). In 2016, membership to the WFCCN has increased and now includes members in Cameroon, Ghana, Nigeria and South Africa, with links in Rwanda and Sierra Leone.

It is hoped through these links, a greater representation of critical care nurses working in low middle income countries and appropriate professional resources can be developed, which will make a real difference to patient care. A greater representation of LMIC within international nursing organisations will challenge those in high income countries to consider how they can support peers in LMIC.

Within Zambia, the network has embarked on the following projects to raise the profile of the network and critical care nursing:

- Professional publications

- Through professional publications and conferences, the network aims to raise the profile and challenges facing critical care nurses in Zambia. In addition, we aim to highlight successes and encourage debate and discussion, but also help develop the art and science of critical care nursing in Zambia.

- International events

- To coincide with World Sepsis day, a series of teaching resources have been developed specifically for Zambia. These resources, can be utilised by members to refresh their understanding of sepsis and the used for peer teaching. Through our network nurses this information was shared and cascaded to nurses within critical care units and ward environments.

- Strengthen the network

- Now established the next stage of the project is to strengthen the position of the network. It is proposed an inaugural network meeting of Zambian Network of Critical Care Nurses; will be held in October 2016. This meeting will provide the strategic direction for the network and agree the next 12 months of professional activities. It is hoped this will provide the foundations for the development of an association.

The future of the network is to develop professional resources and become the voice of critical care nursing. This will be achieved through the development and delivery of workshops and educational resources which will meet the needs of nurses working in Zambia. This will gradually result in the network becoming a source for critical care nursing guidance and strengthening the role of critical care nursing. Longer term aspirations is for the network to I become the authority on critical care nursing and have the ability to recommend and respond to government consultations and nursing strategies. This strategic leadership will ensure the voice of critical care nursing is heard at all levels.

Through partnerships with other LMIC nursing organisations and international organisations, there is an opportunity to develop appropriate guidelines which aim to provide best practice for resource limited environments. These consensus guidelines will provide a benchmark for governments towards and to audit against. Ultimately, this will lead to improve services, which will benefit patients.

Critical care nursing in Zambia has achieved significant progress within a short period of time. This is an exciting time for critical care nurses in Zambia and with international support through the WfCCN this will ensure the momentum is maintained and the voice of nurses is heard at organisational, national and international levels.

\section{REFERENCES}

Carter C (2015). Opportunity to make a difference. Nursing Standard 29(52), 64-65.

Carter C, Snell D (2016). Nursing the critically ill surgical patient in Zambia. British Journal of Nursing 25(20), 1123-1128.

Central Statistics Office (2013). Population composition and distribution. [online]. Available at: http://www.zamstats.gov.zm/ census/cen.html\# Accessed 16 August 2016.

Kinnear JA, Bould MD, Ismailova F, Measures E (2013). A new partnership for anaesthesia training in Zambia: reflections on the first year. Canadian Journal of Anesthesia 60(5), 484-491.

Mulenga U, Malisawa P, Muir N, Bach S (2015). Creating a critical care nursing workforce in Zambia. World Federation of Critical Care Nursing Conference. [online]. Available at: http:// www.wfsiccm2015.com/WFSICCM_AB/1254PMUniverse $\% 20$ Mulenga\%20HIMOONGA.pdf. Accessed 30 July 2016.

Mwewa B, Mweembai P (2010). Knowledge and utilization of ICU Admission criteria and guidelines, Lusaka, Zambia. Medical Journal of Zambia 37(3), 143-152.

The World Bank (2016). Country and lending groups. [online]. Available at: http://data.worldbank.org/about/country-and-lendinggroups\#Lower_middle_income. Accessed 26 July 2016

Williams G, Bost N, Chaboyer W, Fulbrook P, Alberto L, Thorsteinsdottir R, Schmollgurber S, Chan D (2012). Critical care nursing organizations and activities: a third worldwide review. International Nursing Review 59, 73-80.

World Health Organisation (2016). Zambia. [online]. Available at: http://www.who.int/countries/zmb/en/ Accessed 26 July 2016.

World Health Organisation (2015). Health workforce. [online]. Available at: http://gamapserver.who.int/gho/interactive_charts/ health_workforce/NursingMidwiferyDensity/atlas.html Accessed 29 July 2016. 